\title{
Lendo contos de Clarice: uma proposta de avaliação escolar
}

Wellington Augusto da Silva ${ }^{1}$

\begin{abstract}
Resumo:
Nos últimos anos, as pesquisas entre literatura e ensino têm se adensado e produzido um relativo consenso acerca das concepções, dos objetivos e dos pressupostos que estruturam um renovado ensino de literatura na escolarização básica. A fim de contribuir com o referido campo de estudos, buscamos apresentar uma proposta de avaliação, pautada na produção textual de jovens leitores, orientando-nos por Cosson (2007) e Antunes (2006). Para tanto, partimos da experiência que vimos desenvolvendo, o projeto "oficina de poesia" no Colégio Técnico da UFRRJ, cujo objetivo fundamental é o de proporcionar um espaço-tempo escolar, mas não escolarizado, de leitura de poemas e experimentação da linguagem literária. Com as oficinas, notamos que as práticas lá desenvolvidas poderiam ser ferramentas, cuja utilização em sala de aula regular incidiriam no complexo processo de formação literária de jovens leitores. Esse projeto apoiou-se, fundamentalmente, nas concepções estético-pedagógicas de Freire (1996), Lobo (2017) e Pilati (2017). Por fim, ainda que parcialmente, concluímos que as experiências produzidas nas oficinas podem ajudar a redimensionar criativamente a concepção tradicional de avaliação na disciplina.
\end{abstract}

\section{Palavras-chave:}

Ensino de literatura em nível médio. Formação do leitor literário. Contos de Clarice Lispector.

\section{Reading Clarice's tales: an school evaluation proposal}

\begin{abstract}
:
In recent years, researches between literature and teaching have increased and produced a relative consensus about the conceptions, objectives and assumptions that structure a renewed teaching process of literature in basic schooling. In order to contribute to this field of study, we seek to present an evaluation proposal, based on the textual production of young readers, guided by Cosson (2007) and Antunes (2006). So, we started from the experience we have been developing, the project "poetry workshop", at the Technical School of UFRRJ, with a fundamental objective to provide a not schooled school space-time of poetry reading and experiment of literary language. With the workshops, we have noticed that the practices developed there could be tools to be used in the
\end{abstract}

1 Doutor em Teoria Literária pela UFRJ. Professor de Literatura Brasileira e Língua Portuguesa do Colégio Técnico da UFRRJ. E-mail: silva.wa@gmail.com ORCID iD: http://orcid.org/0000-0002-9655-941X 
regular classroom focusing on the complex process of literary formation of young readers. This project was fundamentally based on the aesthetic-pedagogical conceptions of Freire (1996), Lobo (2017) and Pilati (2017). Finally, even partially, we conclude that workshop experiences can help us to creatively resize the traditional conception of assessment in the subject.

\section{Keywords:}

High school literature teaching. Literary reader's education. Clarice Lispector's tales.

\section{Leyendo los cuentos de Clarice: una propuesta de evaluación escolar}

\section{Resumen:}

En los últimos años, la investigación entre literatura y docencia ha crecido y ha producido un relativo consenso sobre las concepciones, objetivos y supuestos que estructuran una renovada enseñanza de la literatura en la enseñanza básica. Para contribuir al referido campo de estudios, buscamos presentar una propuesta de evaluación, basada en la producción textual de jóvenes lectores, guiándonos por Cosson (2007) y Antunes (2006). Para ello partimos de la experiencia que venimos desarrollando, el proyecto "Taller de poesía" en el Colegio Técnico de la UFRRJ, cuyo objetivo fundamental es proporcionar un espacio-tiempo escolar, pero no escolarizado, de lectura de poemas y experimentación con el lenguaje literario. Con los talleres, notamos que las prácticas desarrolladas allí podrían ser herramientas, cuya utilización en el aula regular afectaría el complejo proceso de formación literaria de los jóvenes lectores. Este proyecto se basó, fundamentalmente, en las concepciones estético-pedagógicas de Freire (1996), Lobo (2017) y Pilati (2017). Finalmente, aunque sea parcialmente, concluimos que las experiencias producidas en los talleres pueden ayudar a redimensionar creativamente la concepción tradicional de evaluación en la asignatura.

\section{Palabras clave:}

Enseñanza de literatura en la escuela secundaria. Formación de lectores literarios. Cuentos de Clarice Lispector.

\section{Introdução}

O ponto de partida para a reflexão que aqui se esboça é o chão da sala de aula de um colégio público, vinculado a uma universidade federal, em um município periférico do Rio de Janeiro. Ainda que estejamos em um contexto cercado de carências, de ordens específicas e não generalizáveis, ele nos mobiliza a contribuir com um conjunto mais amplo de reflexões que se desenvolve no campo de debates do ensino de literatura em nível médio.

Seguindo um ensinamento brechtiano, que recomenda partir das coisas ruins do presente e não das boas do passado, as críticas à perspectiva tradicional do trabalho com a literatura em nível médio são de relativo consenso. Seja do ponto de vista do ensino, a centralidade das informações meta-literárias; a transformação dos estilos de época como objeto da disciplina, a simplificação das escolas literárias e sua sucessão cronológica, de corte positivista (como ordenador dos conteúdos em séries); o fragmento de texto em relação mecânica e ilustrativa dos estilos. Seja do ponto de vista da aprendizagem, atividades de avaliação reduzidas a fichas e questionários (quando muito, reveladores dos sentidos explícitos, senão verificação simplista da leitura superficial).

Some-se a esse quadro, o exagero na utilização de nomenclaturas teóricas mescladas, em detrimento da análise literária com vistas à construção de sentidos por parte do leitor em formação. Assim escolarizada, a literatura ainda tem de concorrer com inúmeras outras formas contemporâ- 
neas de entretenimento, que, ao cabo, resulta sem prestígio. Relegada aos últimos degraus no plano da formação humana de potenciais leitores, ela ainda surge como modo de salvação, impregnada de uma aura mística, para a qual somente acessam aqueles que possuem dom transcendente de penetrar nos meandros textuais sacralizados.

A partir dos traços críticos apontados acima, em nossa visão, há um estável consenso acerca dos objetivos e pressupostos que estruturam o ensino de literatura na escolarização básica, em particular em nível médio. São variadas as questões que envolvem o debate acerca da formação do leitor literário, que englobam desde a formação leitora do docente; as concepções de educação, literatura e linguagem; a seleção das obras; as condições concretas de leitura, ensino e aprendizagem com os correspondentes modos de abordagem do texto em sala; eventuais estratégias para a interação texto-leitor, entre outras. Contudo, nosso objetivo, longe de inventariar todas ou comentá-las, é apenas indicar aquelas linhas que nos foram funcionais na condução de um experimento em sala de aula, de nível médio.

Acreditamos que, deste modo, estamos na trilha aberta, há muito, por Paulo Freire (1996, p. 38) de buscar "o movimento dialético entre o fazer e o pensar". Como o pedagogo já ensinou, a formação docente tem como "o momento fundamental da reflexão crítica sobre a prática" (FREIRE, 1996, p. 39) e é, neste sentido, que movemos nossa inquietação por uma prática alternativa ao ensino de literatura em nível médio.

Do ponto de vista mais geral, associamo-nos ao argumento de que a formação do leitor literário no ambiente escolar deva ser atravessada pela mediação concreta da experiência estética, construída pela linguagem verbal. A centralidade que o texto deve assumir, contrapondo ao fragmento ilustrativo, assim como o contato real do jovem leitor com as tramas textuais, é o ponto de partida para acessar uma parte da cultura letrada. Ainda que passível de várias ordens de questionamentos, acreditamos que o acesso a esse extrato da cultura pode facultar também a fruição, ao mesmo tempo em que fomenta a participação do jovem leitor em uma comunidade mais ampla de sentido e pertencimento. Incluída aí a interação profunda "leitor e texto", atenta às suas condições discursivas de produção e recepção, que fomenta tanto a construção de hipóteses de leituras, atribuição de sentido à obra lida como, no limite, posicionamentos autônomos. Em nossa visão, é a peça-chave para a formação integral do indivíduo.

Entendida como um processo em permanente construção, a busca pela formação humana é um compromisso irrecusável da escola contemporânea, cuja meta deveria ser o adensamento do espírito crítico do jovem leitor. Mais uma vez, é o mestre Freire quem nos indica que, no devir da construção da autonomia:

Meu papel fundamental, ao falar com clareza sobre o objeto, é incitar o aluno a fim de que ele, com os materiais que ofereço, produza a compreensão do objeto em lugar de recebê-la, na íntegra, por mim. (FREIRE, 1996, p. 118).

Cremos que o trabalho com a literatura na escola pode ser feito a partir da mediação criativa e criadora do indivíduo singular com a vida, capaz de abrir caminho para o leitor em formação entrar em contato com a sensibilidade construída ao longo do tempo por sujeitos concretos. Assim compreendido, este encaminhamento parece-nos coerente com os objetivos da formação humana ${ }^{2}$. Parece haver concordância entre estes objetivos e os das Orientações Nacionais Curriculares em Literatura, documento que atualizou, desde 2006, o nível médio da educação básica brasileira, no que elas entendem o trabalho com o texto literário como:

20 que foi sumariado é uma pequeníssima parte da compreensão lukacsiana da obra de arte que pode ser acessada em vários escritos do filósofo. A construção de relações com a educação é parte do trabalho de Newton Duarte, de cuja obra Arte e educação contra o fetichismo generalizado na sociabilidade contemporânea (2009) recolhemos nossos comentários. 
A experiência construída a partir dessa troca de significados possibilita, pois, a ampliação de horizontes, o questionamento do já dado, o encontro da sensibilidade, a reflexão, enfim, um tipo de conhecimento diferente do científico, já que objetivamente não pode ser medido. (BRASIL, 2006, p. 55).

Ainda que o foco específico do documento oficial, na parte citada, seja a poesia, este referente pode ser facilmente extensível a todo texto verdadeiramente literário. É preciso, mais uma vez, reafirmar nossa concordância com a presença deste patrimônio humano na escola de modo a obter "cidadania". São, por enquanto, as OCN's que nos afirmam:

Ampliar na escola o circuito de poemas e poetas, quem sabe buscando novas formas de circulação social de poemas, como jornais, revistas (impressos e digitais), e mesmo em outros meios audiovisuais, que, em dobradinha com livros de poemas, permitiriam ver e entender a poesia como uma prática social integrada à vida cotidiana. (BRASIL, 2006, p. 75).

Portanto, ler a poesia no espaço escolar pode ampliar o espaço dela na formação humana dos jovens estudantes. Sendo assim, um compromisso estético e político da escola contemporânea, ao qual ela não poderia se furtar. Na visão de Pilati (2017, p. 12):

A especificidade da literatura está na vivência de experiências humanas através da mediação de uma forma estética particular. E essas vivências são fundamentais não apenas para a formação escolar ou acadêmica do aluno, mas também para o incremento da sua percepção de si mesmo e do mundo, sendo ademais, um sempiterno estimula à intervenção na realidade injusta, que, quase todos concordamos precisa ser transformada e humanizada.

Temos a convicção do alto valor educativo que a arte possui e, por isso trazemos o entendimento que Lobo (2017) confere, ainda que o foco de sua reflexão seja a prática docente em nível superior e a formação de professores:

A potência educativa da estética, da experiência social da criação e da expressão da sensibilidade podem ser armas contra a habitual expropriação dos sentidos, contra a habitual autoridade dos conhecimentos fetichizados pelos editais, contra a habitual negação da psique humana como individualidade rica, subjetividades postas no mundo, tendo a escola, a práxis docente, possibilidades de unir o fazer-se poético, a teorização da experiência social e a prática comunitária. (LOBO, 2017, p. 160-161).

Como se percebe, a aguda consciência do processo social real orienta a atividade docente, por meio de um caminho crítico, que valide e recrie a participação dos educandos.

\section{As possibilidades no ensino de literatura}

A fim de adaptar todas as propostas e orientações renovadoras do ensino de literatura em nível médio, optamos por construir um caminho paralelo, que nos serviu como um laboratório, cuja incidência poderia se irradiar para a sala de aula regular.

O formato assumido foi o de organizar oficinas de poesia para que estudantes, sem qualquer pressão curricular, participassem, e cuja única finalidade era a de ler poemas e experimentar procedimentos literários. Nesse sentido, o núcleo de nossa proposta de oficinas constituiu-se em torno de dois elementos, que julgamos relevantes: da parte dos jovens leitores, o papel ativo na manipulação dos elementos da linguagem literária e na experimentação de recursos artísticos para configurar 
sua subjetividade, com vistas a dar vazão à sensibilidade; e, de nossa parte, coube a apresentação de técnicas e exercícios de estilo e criação, por meio de uma livre interpretação da $\mathrm{OuLiPo}$.

Acerca dela, Alencar e Moraes (2005, p. 11) afirmam: "sem a priori estético, o objetivo do grupo era o de inventar (ou reinventar) regras de tipo formal que pudessem ser propostas a amadores desejosos de produzir textos". As conhecidas práticas das oficinas de escrita criativa baseiam-se em exercícios de estilo com o material verbal, quase sempre agregado ao plano do humor. Por meio das duas autoras, conhecemos duas tendências principais das pesquisas oulipianas, a análise e a síntese:

A primeira refere-se aos trabalhos sobre as obras do passado para procurar nelas possibilidades que ultrapassam com frequência o que seus autores haviam suspeitado. [...] A tendência sintética pretende abrir caminhos desconhecidos por nossos predecessores [...] e no cerne dessa proposta encontram-se, além da exploração da combinatória, as restrições. (ALENCAR; MORAES, 2005, p. 13-14).

Estes procedimentos, que são princípios de estruturação das práticas desenvolvidas nas oficinas de escrita criativa, serviram de base para alguns trabalhos iniciais dos participantes, tendo como objetivo chamar-lhes a atenção para o fato de que, "longe de constranger ou coibir, a restrição [...] é sinônimo de fonte inesgotável de criação” (Alencar; Moraes, 2005, p. 11).

Importante assinalar que nossa prática docente com a leitura estética foi instrumentalizada pela concepção "baseada no tripé: sentir-pensar-agir, com objetivos pedagógicos. Nesse sentido, a metodologia da oficina muda o foco tradicional da aprendizagem (cognição), passando a incorporar a ação e a reflexão" (PAVIANI; FONTANA, 2009, p. 78). Se resolvida, por um lado, a concepção pedagógica, contudo, foi preciso apoiarmo-nos, por outro lado, em uma concepção de literatura mais totalizante que permitisse o diálogo entre diversas formas culturais, assim como a conectar-se com a vida cotidiana dos jovens leitores. Para isso, ao lado do que nos falaram Lobo (2017) e Pilati (2017) acima, trouxemos também a compreensão que Bakhtin possui das relações entre literatura e cultura:

\begin{abstract}
A literatura é uma parte inalienável da cultura, sendo impossível compreendê-la fora do contexto global da cultura numa dada época. Não se pode separar a literatura do resto da cultura e, passando por cima da cultura, relacioná-la diretamente com os fatores socioeconômicos, como é prática corrente. Esses fatores influenciam a cultura e somente através desta, e junto com ela, influenciam a literatura. (BAKHTIN, 1997, p. 362).
\end{abstract}

\title{
Fundamentos para uma avaliação
}

Acreditamos firmemente que, ao ensino de literatura, cabe, entre tantos objetivos, proporcionar aos jovens leitores o alargamento de sua visão de mundo, apresentar-lhes variadas maneiras de experimentar o mundo por meio da linguagem verbal, despertar-lhes possibilidades criativas de organizar suas identidades, por meio do contato integral com a obra literária. Portanto, tentamos produzir uma proposta de produção textual, a partir da leitura de contos de Clarice Lispector e, para tanto, orientou-nos nesse trabalho também a dupla dimensão do efeito estético, assinalada por Regina Zilberman. Para ela, o efeito:

3 A OuLiPo (Ouvroir de Littérature Potentielle) pode ser traduzida como Oficina de Literatura Potencial, que foi uma experiência literária dos anos 1960 na França, cujos nomes mais famosos são George Perec Raymond Queneau e Italo Calvino. A ideia que regia a OuLiPo era a união do rigor matemático à inventividade literária. Por meio da proposição de regras rígidas, criar obras artísticas surpreendentes e com alto teor formal. 
aciona sua fantasia, colocando frente a frente dois imaginários e dois tipos de vivência interior; mas suscita um posicionamento intelectual, uma vez que o mundo representado no texto, mesmo afastado no tempo ou diferenciado enquanto invenção, produz uma modalidade de reconhecimento em quem lê. Nesse sentido, o texto literário introduz um universo que, por mais distanciado da rotina, leva o leitor a refletir sobre seu cotidiano e a incorporar novas experiências. (ZILBERMAN, 2008, p. 7).

Nesse sentido, inclusive, parece-nos coerente trazer uma fala de Rildo Cosson (2007, p. 114), na qual o autor nos indica a validade de gêneros discursivos não usuais nas etapas de avaliação: "é preciso explorar a variedade de gêneros em que o registro escrito pode ser efetivado pelo aluno. Para além do ensaio e da resenha, há o diário de leitura, o relatório, o diálogo e tantas outras formas de registro escrito...”. De modo igualmente válido, sua concepção de que a avaliação em um ensino produtivo de literatura em nível médio deve se caracterizar por "um espaço de negociação de interpretações diferentes. [Sendo] essas negociações que conduzem à ultrapassagem das impressões iniciais [...]" (COSSON, 2007, p. 115).

Em essência, a linha de reformulação do ensino de literatura é uma concepção ativa de sala de aula e de estratégias docentes. Assim, a criatividade e a descoberta são molas propulsoras para esse tipo escola, como espaço para humanização dos indivíduos bem como de democratização dos bens culturais. Embutida aí está a inspiração de a escola proporcionar o aprendizado ativo e conjunto "entre gerações, através do diálogo e da partilha de conhecimentos e de interrogações" (PILATI, 2017, p. 59).

Seguimos uma postura de coordenar as discussões que se seguiram à leitura inicial dos contos selecionados, buscando o registro daquilo que, coletivamente, íamos considerando avanços rumo à complexidade dos textos. Durante cerca de duas semanas de intervalo entre o lançamento da proposta de avaliação e o prazo final de entrega, notamos certo movimento positivo de diálogo entre estudantes para sua realização, bem como engajamento na realização da tarefa escrita. Parece ter havido tanto o que Regina Zilberman (2008, p. 17) nos apresenta: "O leitor tende a socializar a experiência, cotejar as conclusões com as de outros leitores, discutir preferências. A leitura estimula o diálogo, por meio do qual se trocam resultados e confrontam-se gostos.", como o que Cosson (2007, p. 113) nos ensina: "Só assim se poderá aprofundar os sentidos que se construiu para aquela obra e fortalecer o processo de letramento literário individual e de toda a turma".

Para o docente já experimentado no trabalho com a disciplina e sua organização tradicional, a chamada prosa da $3^{a}$ fase modernista é um dos tópicos reservados ao $3^{\circ}$ ano do ensino médio. Há uma dupla justificativa para este espaço na grade curricular: a conhecida lógica historiográfica e uma suposta maturidade dos adolescentes concluintes do ensino médio a encararem uma prosa dotada de procedimentos de vanguarda e uma apurada reflexão existencial sobre a condição humana.

Aproveitando as brechas existentes no currículo formal e utilizando da relativa autonomia docente, apresentamos uma proposta de leitura de contos de Clarice Lispector às nossas turmas de $3^{\circ}$ ano, que previa uma avaliação de caráter criativo.

\section{Proposta de produção textual e avaliação para a leitura dos contos de Clarice}

O desafio lançado teve como ponto inicial a leitura de dois contos, "Tentação" e "Amor", bastante conhecidos da escritora. O primeiro lido em sala e em detalhes, na tentativa de se constituir em uma leitura imanente do gênero textual: levantamento de hipóteses acerca do título da obra e verificação/comprovação/surpresa ao final da leitura; indicação de sua estrutura formal e elementos destacados da narrativa; os pontos de inflexão do conto, a construção do suspense e o desfecho; a caracterização da personagem. Com esses passos, tentamos formar um acervo de recursos 
discursivos e literários que pudessem indicar a grande inventividade da prosa de Clarice. Isto é, um estudo sobre a configuração do gênero em tela e a função desses elementos para a construção de sentido, a fim de que os jovens leitores pudessem experimentar aquela linguagem. Como percebido, pouquíssima preocupação com estilo de época, escola literária ou uma contextualização histórica mecânica e muito interesse no contato detido com um conto representativo da obra clariceana.

Em seguida, um debate oral para a exposição de elementos que despertaram a curiosidade e a atenção da turma. Aqui, quase unanimidade, a automática identificação dos leitores com a triste solidão das protagonistas. As reações mais significativas já demonstravam um sentimento catártico em relação à leitura de "Tentação". Estava dado o momento de reflexão sobre uma das características que fundam uma vertente de corte filosófico-existencial da prosa de Clarice. Instruídos também pelo tripé fundante de nossas atividades na oficina (leitura, reflexão e produção), pudemos mais claramente reposicionar o conceito de epifania, importante para certa fortuna crítica da escritora. Este, compreendido, à luz de Adam (2005, p. 26), como:

a percepção de uma realidade atordoante quando os objetos súbita iluminação na consciência dos figurantes. Ao dar-se a epifania, a consciência do indivíduo se abre para outra realidade como sendo a "realidade atordoante" invocada por atos banais do dia-a-dia.

Assim, o conceito só se tornou válido na medida em que aprofundou a leitura dos jovens leitores, tornando-os aptos a reconhecerem situações semelhantes em sua experiência cotidiana. Longe, portanto, de ele próprio ser um critério validador ou não da obra ficcional. Feitas as considerações acerca do conceito de "epifania", pediu-se à turma que anotasse uma situação que pudesse ser caracterizada como tal.

Evidentemente, não está em discussão o eventual valor literário da produção textual do jovem leitor, mas sim a demonstração de envolvimento com a leitura dos contos, a percepção do conceito - importante para a maquinação verbal da escritora - e as habilidades escritas para a produção textual. Nesse ponto, o modelo composicional escolhido teve relação direta com a lógica formal dos contos da escritora. Como gênero textual a ser trabalhado, elencamos aquele que nos pareceu adequado à situação de leitura: a reflexão pessoal.

Poder-se-ia argumentar que se trata de um gênero textual inadequado para adolescentes leitores em formação, ainda carentes de significado para sua vida e inaptos à percepção do sentido profundo de vivências. Além disso, do ponto de vista da prática docente, colocamo-nos mais esse desafio pedagógico, e de cunho talvez ético: elevar ao caráter de avaliação (um dos principais ritos escolares) a sensibilidade e a imaginação criadora dos jovens leitores em formação.

Diante de tudo isso, gostaríamos de verificar, com esta proposta, se as atividades de leitura imanente feitas formaram um acervo acessível para os estudantes, forte o suficiente para plasmar sua experiência, por meio de suas descobertas da linguagem artística. Ou seja, estávamos interessados em demonstrar ser possível uma avaliação escolar que depurasse, por meio da escrita, as vivências sensíveis e cotidianas dos jovens, a partir da obra estética de Clarice.

Os contos da escritora se tornaram pontos de partida para uma tomada de posição acerca das vivências dos jovens leitores. Por este ângulo, tanto mais produtiva seria a reflexão pessoal dos estudantes quanto mais profundamente eles configurassem seus olhares para seu entorno, no sentido de extrapolar o cotidiano reificado e petrificado pela rotina da mercadoria e da indústria cultural. De outro modo, a proposta de avaliação seria uma espécie de exercício de afastamento dos perigos causados por hábitos irrefletidos e pelo embotamento da sensibilidade, para uma formação estética.

Por estarmos em um terreno da prática docente eivado de contradições e imprecisões, foi necessária a busca por elementos objetivos a constituírem o processo de avaliação escolar, ao lado da materialização verbal da criatividade dos jovens leitores. Por isso, recorremos a Irandé Antunes 
(2006), em seu “A avaliação da produção textual no ensino médio", a fim de recolher procedimentos e critérios, que pudessem redimensionar a avaliação da produção em tela.

Em seu artigo, Antunes apresenta vários comentários fundamentais a uma prática renovada de avaliação em nível médio, direcionadas à produção textual. Embora seja referida a dimensão mais geral dos textos, é evidente o foco nos gêneros não-literários, o que para nosso interesse foi de grande valia, posto que a dimensão artística não deveria ser a razão primeira da escrita dos jovens leitores.

Além das considerações de caráter geral da avaliação da aprendizagem, na proposta de Antunes, há três parâmetros bastante detalhados, relacionados especificamente à avaliação da produção textual (linguísticos, de textualização e pragmáticos) que nos foram muito caros. A partir da proposta da autora, constituímos como nossos critérios:

a. atenciosa escolha lexical, com vistas à construção do ponto de vista singular da reflexão dos estudantes;

b. utilização da intertextualidade como ferramenta válida na criação de uma voz autoral, como estratégia de funcionamento da reflexão pessoal. Demonstrado, assim, reelaboração de temas, figuras e formas, por parte dos estudantes, a partir do contato com os contos, o envolvimento com seus pontos de vista narrativos e o conjunto de valores neles configurados;

c. O atendimento ao gênero textual reflexão pessoal, que por estar na fronteira dos domínios, demandava a exposição tanto de uma situação considerada pelos estudantes como típica da epifania bem como narrada sob um ponto de vista eminentemente pessoal.

\section{Considerações finais}

A realidade contemporânea brasileira, a cada dia, coloca mais desafios ao magistério, em suas múltiplas dimensões de atuação. Seja na sua relação contraditória mais geral com a sociedade e a correspondente desvalorização salarial e amplo descrédito, seja na descrença da atividade docente por vários agentes públicos, ou no desejo de sentido que os estudantes expressam cotidianamente a seus professores.

A lógica que organiza a experiência de trabalho aqui relatada é a promoção ao acesso, contato e leitura de materiais estéticos com vistas ao alargamento cultural de jovens estudantes, possibilitando, ainda que modestamente, uma formação escolar aberta à dimensão do sensível. Está em jogo, portanto, a defesa da escola pública como promotora de um ensino afeito à forma estética. Isto é, defendemos que o conhecimento pode se dar de forma mais totalizante. Ao lado da razão, que orienta a análise e o estudo sistematizado de fenômenos, o plano da criação artística, da experimentação da linguagem verbal. Em nossa visão, estas duas dimensões podem confluir para a formação humana total.

O ponto de partida que orientou a inquietação mais uma vez foi Paulo Freire (1996), ao afirmar que, para ensinar, é necessário escutar e que, precisamente por isso, a prática educativa deve ser pautada pelo falar com e não apenas o falar para o estudante. Acreditamos que nossa proposta de avaliação contribui para o reposicionamento deste momento do processo de ensino-aprendizagem, assim como para o redimensionamento da relação do leitor com o texto literário.

No sentido que conferimos até agora à nossa exposição, foram importantes dois apontamentos do artigo já citado de Roberta Lobo (2017), cuja finalidade é impulsionar nossa proposta de avaliação para o contato daqueles jovens leitores, em 2018, de Clarice Lispector. De um lado, a pergunta: "Como perfurar este bloqueio de uma realidade inóspita para a imaginação criadora no cotidiano de professores e alunos e avançar na formação estética destes sujeitos?” (LOBO, 2017, p. 165), de outro, a afirmativa: 
A experiência estética como práxis não é apenas o acesso à cultura universal, mas práxis que faz conhecer o mundo e a si mesmo com olhos de poeta, tendo na consciência sonhadora a centelha que mantém viva a prática da educação pela sensibilidade. (LOBO, 2017, p. 171).

Dessa forma, acreditamos trabalhar na linha de que educação possa não ser apenas instrumento de reprodução das desigualdades, treinamento de habilidades e competências a serem testadas em exames de larga escala, ou coisa que o valha. Ou seja, algo próximo do que Dalvi (2018, p. 299) nos indica:

formação omnilateral do ser humano pelo desenvolvimento crítico de sua inteligência, emoção e sensibilidade em diferentes campos artísticos, científicos e filosóficos, visando à participação ativa e consciente na transformação das condições de vida humanas, em um contexto histórico e social complexo.

A opção pelo texto de Clarice Lispector, no final da escolarização básica, se deve fundamentalmente pelo traço enfático da subjetividade, o modo singular de estar no mundo, reconhecendo-lhe o movimento extraordinário do cotidiano mais banal. Os meios artísticos internos dos contos nos pareceram um bom caminho para contribuir com uma etapa no processo de formação do jovem leitor, na exata medida em que sua forma artística dá a ver a esse leitor mecanismos de espanto e estranhamento diante do mundo repetitivo e corriqueiro, em que estamos todos inseridos.

Instruídos pelo texto de Clarice, acreditamos haver espaço para nosso singelo recorte de uma proposta de leitura literária em que valorize a autoria e a percepção sensível do jovem leitor, compreendendo-o como possuidor de voz merecedora de audiência e interlocução. Renovando, pois, o acervo de sentidos imanentes ao texto canônico, proporcionando um enriquecimento da subjetividade do leitor, através da literatura, suscitando uma avaliação crítica sobre seu mundo. Ou ainda acompanhados por mais um ensinamento do educador, que ensinou docentes que escutar: "significa a disponibilidade permanente por parte do sujeito que escuta para a abertura à fala do outro, ao gesto do outro, às diferenças do outro" (FREIRE, 1996, p. 119).

Encerramos nossa reflexão como as palavras finais do artigo "Em defesa do direito de ler", das professoras Célia Sebastiana Silva e Viviane Fleury de Faria (2018, p. 110), com as quais elas concluem:

o sentido de uma leitura literária profícua só existe verdadeiramente quando faculta ao aluno leitor a possibilidade de desenvolver a sua autorreflexão crítica, o aprofundamento da sua subjetividade, uma formação humana, ética e estética que efetivamente possa emancipá-lo como cidadão e possibilitar-lhe, socialmente, a conquista plena da autonomia.

\section{Referências}

ADAM, Marcia Regina Cândido Otto. Clarice Lispector e Franz Kafka: trilhas e vislumbres. 2005. Dissertação (Mestrado em Literatura Brasileira) - Universidade Federal de Santa Catarina, Florianópolis, 2005. Disponível em: http:// www.tede.ufsc.br/teses/PLIT0194.pdf. Acesso em: 02 abr. 2021.

ANTUNES, Irandé. Avaliação da produção textual em nível médio. In: BUZEN, Clécio (org.). Português no ensino médio e formação do professor. São Paulo: Parábola Editorial, 2006. p. 163-180.

ALENCAR, Ana Maria; MORAES, Ana Lúcia. O OULIPO e as oficinas de escrita. TERCEIRA MARGEM: Revista do programa de pós-graduação em Ciência da Literatura, Rio de Janeiro, ano 9, n. 13, p. 9-29, jul./dez. 2005. 
BAKHTIN, Mikhail. Estética da Criação Verbal. São Paulo: Martins Fontes, 1997.

BRASIL. Secretaria de Educação Média e Tecnológica. Orientações Curriculares para o Ensino Médio. Brasília, DF: Ministério da Educação, 2006. Disponível em: https://portal.mec.gov.br/seb/arquivos/pdf/book_volume_01_internet. pdf. Acesso em: 02 abr. 2021.

COSSON, Rildo. Letramento literário: teoria e prática. São Paulo: Contexto, 2007.

DALVI, Maria Amélia. Educação literária: história, formação e experiências. In: DALVI, Maria Amélia et al. (org.). Literatura e educação: história, formação e experiência. Campos dos Goytacazes: Brasil Multicultural, 2018. p. 12-24.

DUARTE, Newton. Arte e educação contra o fetichismo generalizado na sociabilidade contemporânea. Perspectiva, Florianópolis, v. 27, n. 2, p. 461-479, jul./dez. 2009. Disponível em: https://periodicos.ufsc.br/index.php/perspectiva/ article/view/2175-795X.2009v27n2p461. Acesso em: 02 abr. 2021.

FREIRE, Paulo. Pedagogia da autonomia. Saberes necessários à prática docente. São Paulo: Editora Paz e Terra, 1996.

LOBO, Roberta, Docência e estética: armas contra o habitual. In: ALBUQUERQUE, Gregório Galvão de (org.). Cultura, politecnia e imagem. Rio de Janeiro: EPSJV, 2017. p. 159-174. Disponível em: https://www.arca.fiocruz.br/bitstream/ icict/26102/2/Livro\%20EPSJV\%20013772.pdf. Acesso em: 02 abr. 2021.

PAVIANI, Neires; FONTANA, Niura. Oficinas pedagógicas: relato de experiência. Conjectura, Caxias do Sul, v. 14, n. 2, maio/ago. 2009. Disponível em: http://www.ucs.br/etc/revistas/index.php/conjectura/article/viewFile/16/15. Acesso em: 02 abr. 2021.

PILATI, Alexandre. Poesia na sala de aula: subsídios para pensar o lugar e a função da literatura em ambientes de ensino. Campinas: Pontes Editores, 2017.

SILVA, Célia Sebastiana; FARIA, Viviane Fleury de. Em defesa do direito de ler. In: DALVI, Maria Amélia et al. (org.). Literatura e educação: história, formação e experiência. Campos dos Goytacazes: Brasil Multicultural, 2018. p. 102-110. Disponível em: https://literaturaeeducacao.ufes.br/sites/grupoliteraturaeeducacao.ufes.br/files/field/anexo/ebook_literatura-educacao_historia_formacao_experiencia_0.pdf. Acesso em: 02 abr. 2021.

ZILBERMAN, Regina. O papel da literatura na escola. Via Atlântica, São Paulo, n. 14, p. 11-22, dez. 2008. Disponível em: http://www.revistas.usp.br/viaatlantica/article/view/50376. Acesso em: 02 abr. 2021.

Data de submissão: 08/03/2021

Data de aceite: 01/04/2021 